\title{
Transmission of Impact Vibration on Concrete and Mortar Sheets
}

\author{
Carlos Morón, ${ }^{1}$ Alfonso García, ${ }^{1}$ Daniel Ferrández, ${ }^{1}$ and Víctor Blanco ${ }^{2}$ \\ ${ }^{1}$ Departamento Tecnología de la Edificación, Universidad Politécnica de Madrid, 28040 Madrid, Spain \\ ${ }^{2}$ Colegio Santísima Trinidad, Alcorcón, 28925 Madrid, Spain
}

Correspondence should be addressed to Alfonso García; alfonso.garciag@upm.es

Received 29 March 2015; Revised 25 May 2015; Accepted 3 June 2015

Academic Editor: Longjun Dong

Copyright (C) 2015 Carlos Morón et al. This is an open access article distributed under the Creative Commons Attribution License, which permits unrestricted use, distribution, and reproduction in any medium, provided the original work is properly cited.

The present work exposes an alternative system for detecting vibrations generated by impact on concrete and mortar sheets. In order to carry out the tests it is necessary to implement a system of measurement different than the one proposed by the current UNE EN 140-7. This system consists of an amplifier and a striking device that is also able to measure the deformation of the material once the impact has been produced. This system is able to detect variations in transmission of vibration at the same frequency between the various building materials employed, after establishing a relationship between the theoretical predictions and the experimental results. Thus, this system could be used as a vibration detection system and as an alternative method of standardization of materials against their acoustic characteristics.

\section{Introduction}

Currently, there are many tests to better understand the importance of the vibration transmission in materials and its applications in the building field. The current legislation at national level is contained in the Technical Building Code (CTE DB-HR) [1] and in the present Instruction for Structural Concrete (EHE-08) [2] and at international level through ISO standards, where the importance of acoustically characterizing materials against their impact noise reduction is stated as improvement of quality and comfort of the rooms built.

Some studies focus on the vibrations caused by people, when they perform dynamic actions on the building floor area [3]. These vibrations may significantly affect the service behavior but rarely the fatigue behavior and the safety of the structure. Beyond the noise produced, these actions generate frequencies that can be detected and measured by means of the necessary instrumentation and differ depending on the use that has the built-up area that is to be measured. Another source of vibrations, which also becomes very important in building, is the facilities that generate annoying noises and is detectable by transmission through the structure even several meters away from the emitting center. The isolation of these vibrations and the study of materials that allow a greater acoustic absorption have already been studied by other researchers and it is still improving today.

Among the works that include the use of vibration to determine certain physical parameters of the materials, there are different tests dependent on the material and the measurable characteristics. Some authors produced small mechanical disturbances in the test tubes and the reported results correlated with the help of appropriate software with other standardized techniques such as using ultrasound or conventional bending tests, subsequently making the analysis of harmonics given by the Fast Fourier Transform to determine the dynamic Young modulus of the material $[4,5]$. At other times, the work is done with materials reinforced with some type of fibers or additives, and a research is carried out on the improvement obtained due to the addition of that material both structurally and acoustically; these tests generally measure the relationship between flexural toughness and impact-induced energy [6]. Also, in the case of concrete and mortar, a comparison was made between the different fundamental resonant frequencies of the materials transversely vibrated without any restriction $[7,8]$. 


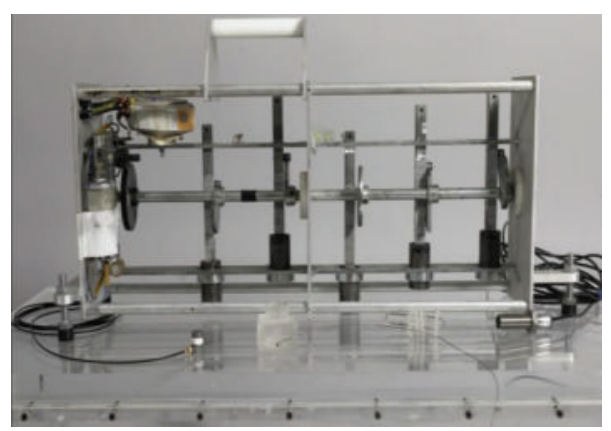

(a)

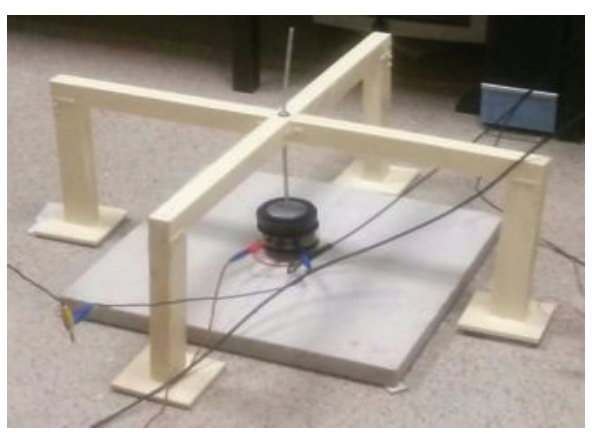

(b)

FIGURE 1: (a) Striking device listed on the UNE EN 140-7. (b) Alternative striking device.

The purpose of this comparison was to study the influence on the durability of them after undergoing several freeze-thaw cycles [9].

When working with building structures the process changes, since the dimensions are greater. Furthermore, it is important to distinguish between different existing joints in the structures because a rigid embedment would act as a single piece against the transmission of the vibration, whereas a support would remain the union between pieces unbonded, without stiff junction, attenuating the noise impact [10]. When studying the behavior of floor-framing against impact noise, excitations similar to those in the footsteps are analyzed, and to do this a known mass is rhythmically dropped from a predetermined height. Whatever the force of the impact transmitted to the floor-framing will produce deformation of the material in the area occupied by the body, sliding it from its equilibrium position until the elastic forces of the floor-framing return to its initial position. This originates a vibration wave, which propagates with longitudinal speed that depends on the nature of the material composing the floor-framing (the density of the material and the dynamic elastic modulus), where generally, for the same density, the higher the elastic modulus the higher the transmission speed, and this vibration is in charge of generating the airborne noise to be controlled [11]. Most of the tests carried out in this area have been assigned to the study of the floating slab as the most appropriate constructive solution to reduce the noise impact, characterizing the different materials that can be used as a separator sheet between the rigid surface and the floorframing's structure.

Other investigations focus on the development or improvement of the measurement and detection of vibrations devices. In these cases, the materials are not as important as the sensitivity of the devices and the measurement procedures [12]. Some tests are based on the physical concept of mechanical resonance and attempt to measure the resonance frequencies of the different materials. However, others are responsible for the development of sensors capable of detecting the impact produced on a certain area measuring a physical parameter which might be capacity, speed, or pressure [13-21].

The aim of this paper is to develop an alternative system of measurement that can detect vibrations produced on the surface of two different materials (concrete and mortar), analyzing the differences in sensor response for each of the plates and verifying the validity of the system implemented as an alternate measurement method for detecting vibrations in building structures.

\section{Methodology}

2.1. Materials That Have Been Used. Two tiles were made for this study, one of concrete and another one of mortar, without any type of frame to increase its resistance to bending. Since the measuring device is responsible for detecting transverse vibration produced after the impact, it is important that the tile resembles as much as possible the vibration model of a stretched membrane. Therefore, it is essential that the tiles produced work on both main directions and may be considered to be plates instead of sheets. For this purpose, the idea that the thickness must be less than a quarter of the length of the tile, as required by the current EHE-08, was used as a premise.

The dimensions of the tiles were $50 \times 50 \times 4 \mathrm{~cm}$, and the dosage by weight used was $1: 3: 0.5$ (cement/sand/ water) in the case of the mortar and $1: 2: 3: 0.5$ (cement/ sand/gravel/water) in the case of the concrete. It was attempted to obtain a soft consistency controlling the amount of water introduced; with this, once the hardening begins, it evaporates leaving recesses inside which may distort the test results. To prevent this trapped air, the concrete and the mortar were conveniently vibrated to overcome the cohesive forces of the material and to allow the adaptation to the mold, equally distributing the mixture and avoiding significant differences in the composition of the tile.

2.2. The Striking Device. The striking device listed on the UNE EN 140-7 for testing against impact noise provides that it must have five hammers lined with insulating feet vibration, separated from each other a distance of approximately $10 \mathrm{~cm}$ and each of them periodically hits with a metal mass of $500 \mathrm{~g}$ and a ball nose end with a radius of $50 \mathrm{~mm}$ from a height of $40 \mathrm{~mm}$ (Figure 1(a)). In this work, a wooden frame was used as an alternative whose bases are insulated against vibrations with an electromagnetic vibrator hanging, covered by a steel 


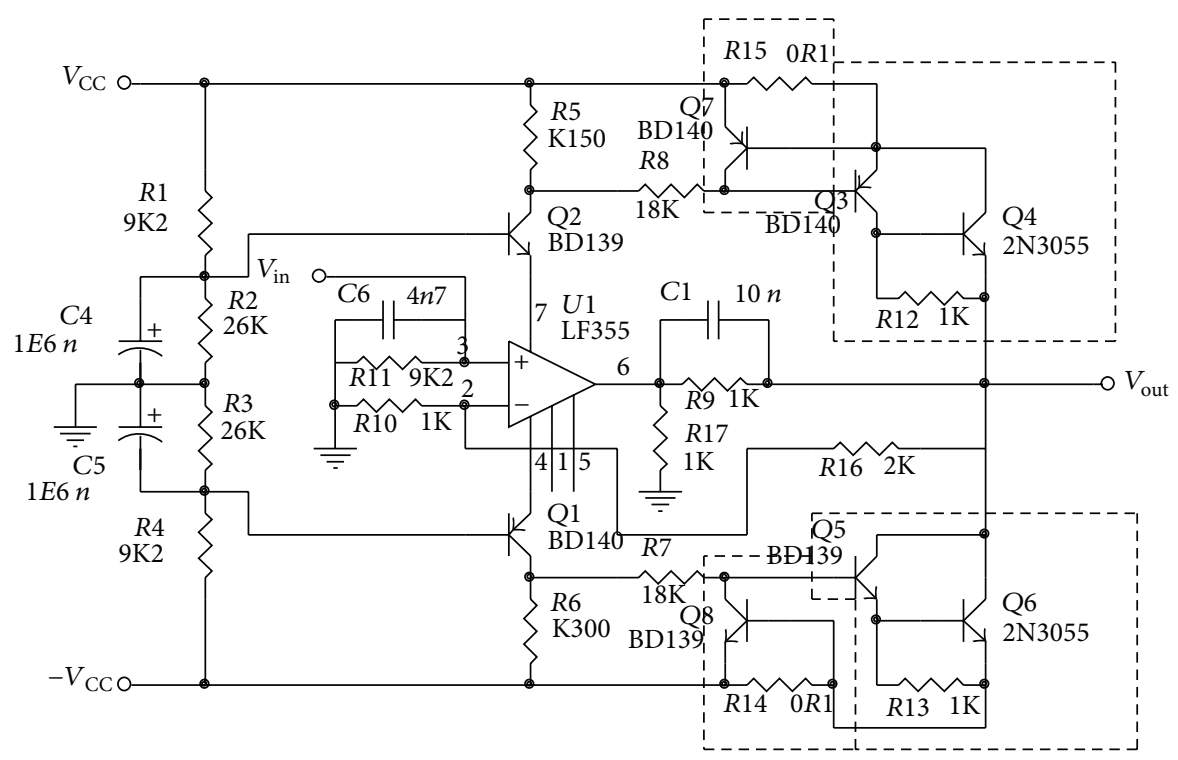

FIGURE 2: Electrical diagram of the power amplifier.

casing containing a field winding where the armature moves linearly as they vary the frequency of the alternating voltage to which it is connected (Figure 1(b)).

2.3. Design of the Measuring Equipment. The measuring equipment consists of several parts. Firstly, a power amplifier was designed, since the electrical signal from the function generator was not stable enough to be sent directly to the vibrator that strikes the plate. The system devised is capable of amplifying signals of frequency below $15 \mathrm{kHz}$ and the amplifier consists of a first stage that allows us to add a continuous and controlled potential to the signal. On the other hand, the general characteristics of the amplifier are as follows: voltage gain factor is 10 , the maximum output current is $1 \mathrm{~A}$, the maximum output voltage is $30 \mathrm{~V}$, short-circuit protection and amplification without appreciable distortion are from $0 \mathrm{~Hz}$ to $10 \mathrm{kHz}$. The generator and the amplifier apply signals of frequency very stable and variable, which can be regulated at all times. See the electrical diagram of the amplifier in Figure 2.

Moreover, a sensor was designed that was capable of measuring the transverse deformation produced when the tile is struck on its upper face, knowing the striking energy, selected with the help of the vibrator. The sensor consists of a condenser that is part of a digital self-oscillating circuit. The output of this circuit is connected to an FM Demodulator tuned to a frequency which is the base frequency of the selfoscillating circuit. The diagram of the sensor is shown in Figure 3.

As the capacity of the condenser depends only on its geometry and the matter permittivity between plates, if the area between its plates and the dielectric is kept constant, then its capacity will only vary depending on the separation between the plates. One of the plates of the transducer is fixed in the middle of the plate material (as can be seen in Figure 4), while the other one is fixed on the flat reference

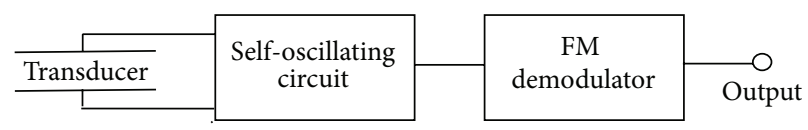

Figure 3: Diagram of the sensor.

surface, so that when the impact occurs, the transverse deformation produced by the vibration varies the capacity of the condenser, whose signal is recorded.

The self-oscillating circuit is constructed such that its natural oscillation frequency is sufficiently high, in this case $3.3 \mathrm{MHz}$. On the other hand, the size of the plates must always be less than or equal to half of a wavelength so that the sensor sensitivity corresponds to the measures taken; therefore, knowing the propagation speed of the transverse wave in the medium can set the dimensions of the condenser plates. To calculate the propagation velocities the following formulas were used for concrete (i) and mortar (ii):

$$
\begin{aligned}
& \text { (i) } V_{t}=\sqrt{\frac{E_{d} \cdot g}{\gamma_{H}} \cdot \frac{1}{2 \cdot(1+\nu)}}=2450 \mathrm{~m} / \mathrm{s} \\
& \text { (ii) } V_{t}=\sqrt{\frac{E}{2 \gamma_{M} \cdot(1+\nu)}}=1225 \mathrm{~m} / \mathrm{s},
\end{aligned}
$$

where $E_{d}$ is the dynamic modulus of elasticity of concrete $\left(3,23 \times 10^{9} \mathrm{~kg} / \mathrm{m}^{2}\right), E$ is the elastic modulus of mortar $(9 \times$ $\left.10^{6} \mathrm{MPa}\right), \gamma_{H}$ is the concrete density $\left(2200 \mathrm{~kg} / \mathrm{m}^{3}\right), \gamma_{M}$ is the mortar density $\left(2500 \mathrm{~kg} / \mathrm{m}^{3}\right), g$ is acceleration of gravity $\left(9.8 \mathrm{~m} / \mathrm{s}^{2}\right)$, and $v$ is the Poisson coefficient (0.2). Taking into account that condenser plates are $6 \mathrm{~cm}$ per side, the length of 


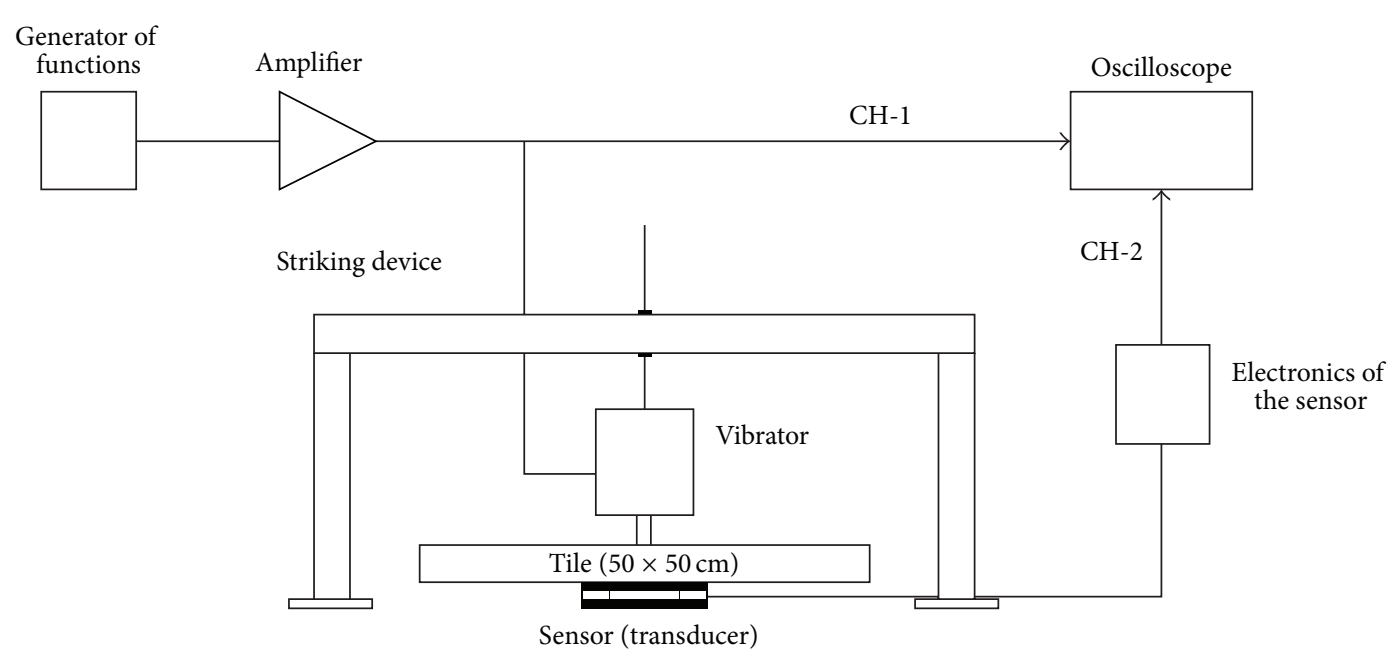

FIGURE 4: Diagram of the measuring equipment.

the transverse wave should be at most $12 \mathrm{~cm}$. Thus, we obtain a frequency $(f)$ for concrete (i) and mortar (ii) as follows:

(i) $v=\lambda \cdot f \Longrightarrow 2450=0.12 \cdot f \Longrightarrow f=20417 \mathrm{~Hz}$

(ii) $v=\lambda \cdot f \Longrightarrow 1225=0.12 \cdot f \Longrightarrow f=10208 \mathrm{~Hz}$.

That is within the range of our oscillating circuit.

Finally, the variation in the capacity of the transducer reproduces the concrete or mortar sheet deformation, and this leads to the output of the self-oscillating circuit a frequency modulated signal. The frequency modulation is due to transverse vibration, so adding the demodulator circuit, a signal proportional to the transverse deformation of the mortar or concrete sheet is obtained at the output of the circuit at each time point. This signal was collected with the help of an oscilloscope (Figure 4).

\section{Results and Discussion}

Figure 5 shows the excitation signal with a frequency of $10000 \mathrm{~Hz}$. With this, we have obtained the sensor response and its analysis of harmonic numbers for concrete (Figure 6) and mortar (Figure 7) tiles. As can be seen, the sensor response and the harmonic analysis for a prefixed frequency of work show differences between the tiles of concrete and mortar. The data that were used for the analysis harmonics were treated using a software programmed capable of calculating the discrete Fourier transform, thereby obtaining a representation in the frequency domain, with the original function being a function in the time domain.

As can be appreciated in the graphics, the sensitivity of the sensor is able to differentiate the modes of transmission of the impact between the different materials, being higher in the case of concrete than in the case of mortar, which is consistent with the previous theoretical calculations.

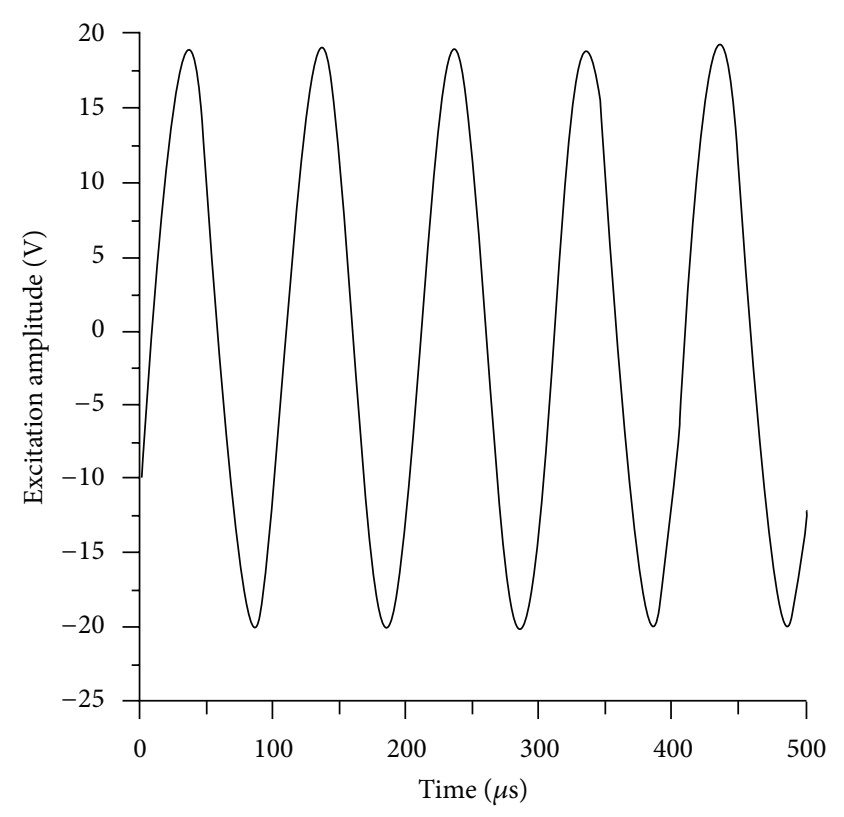

FIGURE 5: Excitation signal with a frequency of $10000 \mathrm{~Hz}$.

\section{Conclusions}

From the data obtained it can be stated that we have developed, on the one hand, a system that is able to produce measurable and controllable vibrations and, on the other hand, a transducer that is able to appreciate the frequency variations caused by the striking device, giving a signal in response which is easily analyzable.

Studying the harmonic content of the sensor response in the cases of concrete and mortar clearly differentiated results has been obtained. The frequency of response has been higher in the case of concrete. This is consistent with the theoretical results obtained in (2) and therefore verifies the validity of the equipment. The developed system can be improved to achieve higher sensitivity and sharper responses. 


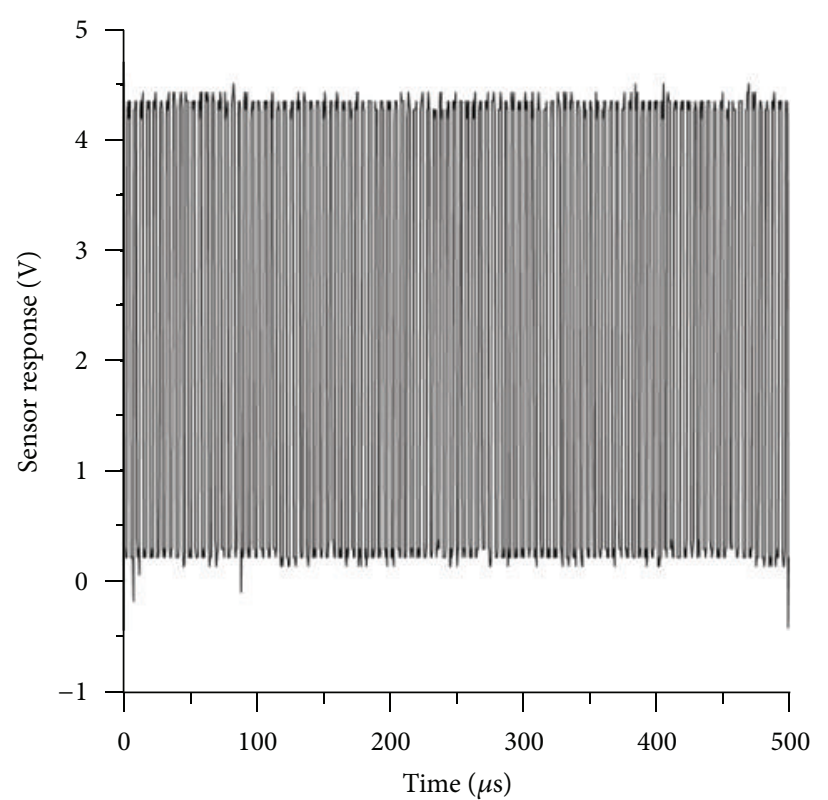

(a)

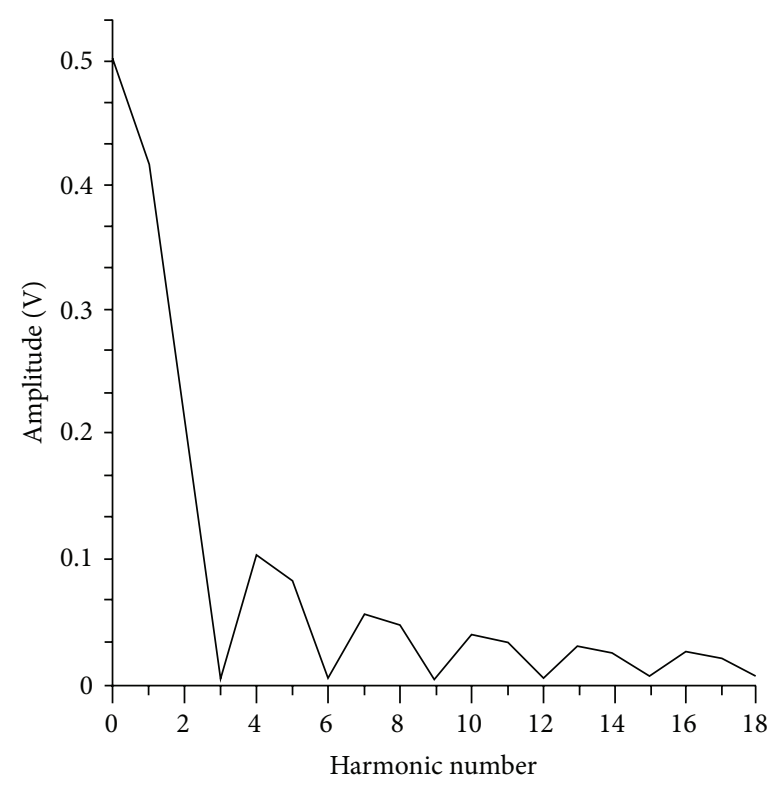

(b)

FIgURE 6: Response concrete tile. (a) Response of the oscillator. (b) Analysis gives harmonics of the sensor response.

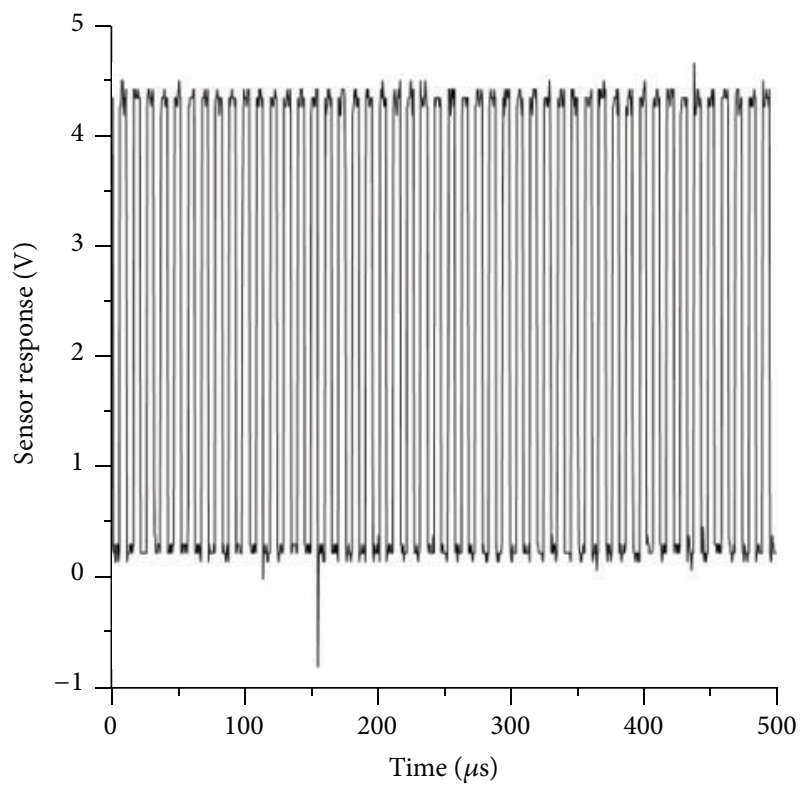

(a)

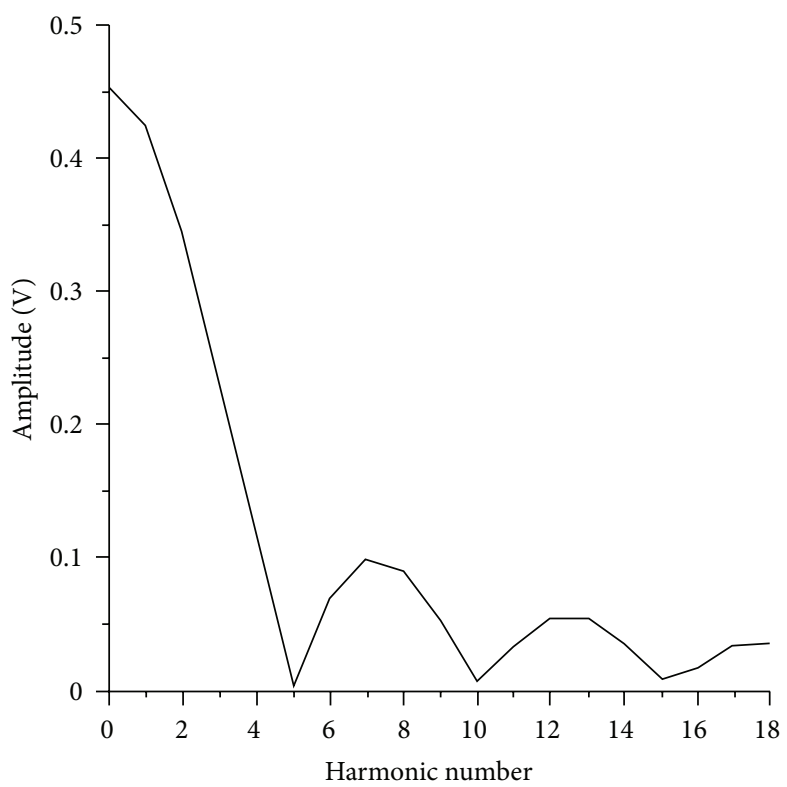

(b)

FIGURE 7: Response mortar tile. (a) Response of the oscillator. (b) Analysis gives harmonics of the sensor response.

Thus, through a more thorough process, the system could be used as standard method for the study of vibrations and acoustic insulation against impact noise.

\section{Conflict of Interests}

The authors declare that there is no conflict of interests regarding the publication of this paper.

\section{References}

[1] España, Código Técnico de la Edificación, Boletín Oficial del Estado, 2006.

[2] España, "Instrucción de Hormigón Estructural," Boletín Oficial del Estado, núm. 203, 2008.

[3] M. Tarabini, S. Solbiati, G. Moschioni, B. Saggin, and D. Scaccabarozzi, "Analysis of non-linear response of the human body to vertical whole-body vibration," Ergonomics, vol. 57, no. 11, pp. 1711-1723, 2014. 
[4] A. Nagy, "Determination of E-modulus of young concrete with nondestructive method," Journal of Materials in Civil Engineering, vol. 9, no. 1, pp. 15-20, 1997.

[5] D. Dai and Q. He, "Structure damage localization with ultrasonic guided waves based on a time-frequency method," Signal Processing, vol. 96, pp. 21-28, 2014.

[6] K. Marar, Ö. Eren, and T. Çelik, "Relación entre la tenacidad a flexión y la energía de impacto en hormigones de alta resistencia reforzados con fibras," Materiales de Construcción, vol. 51, no. 262, pp. 5-13, 2001.

[7] L.-Q. Chen, W.-J. Zhao, and J. W. Zu, "Simulations of transverse vibrations of an axially moving string: a modified difference approach," Applied Mathematics and Computation, vol. 166, no. 3, pp. 596-607, 2005.

[8] L.-Q. Chen and H. Ding, "Steady-state transverse response in coupled planar vibration of axially moving viscoelastic beams," Transactions of the ASME-Journal of Vibration and Acoustics, vol. 132, no. 1, Article ID 01100919, 9 pages, 2010.

[9] E. K. Schrader, "Impact resistance and test procedure for concrete," Journal of the American Concrete Institute, vol. 78, no. 2, pp. 141-146, 1981.

[10] A. H. Hosseinloo, F. F. Yap, and L. Y. Lim, "Design and analysis of shock and random vibration isolation system for a discrete model of submerged jet impingement cooling system," Journal of Vibration and Control, vol. 21, no. 3, pp. 468-482, 2015.

[11] J. Wu, W. Lei, Q. Wu, Y. Wang, and L. Ma, "Transverse vibration characteristics and stability of a moving membrane with elastic supports," Journal of Low Frequency Noise Vibration and Active Control, vol. 33, no. 1, pp. 65-78, 2014.

[12] M. Ghajari, Z. Sharif-Khodaei, M. H. Aliabadi, and A. Apicella, "Identification of impact force for smart composite stiffened panels," Smart Materials and Structures, vol. 22, no. 8, Article ID 085014, 2013.

[13] R. Makowski and R. Zimroz, "New techniques of local damage detection in machinery based on stochastic modelling using adaptive Schur filter," Applied Acoustics, vol. 77, pp. 130-137, 2014.

[14] D. W. T. Wundersitz, P. B. Gastin, C. Richter, S. J. Robertson, and K. J. Netto, "Validity of a trunk-mounted accelerometer to assess peak accelerations during walking, jogging and running," European Journal of Sport Science, vol. 15, no. 5, pp. 382-390, 2014.

[15] R. Klöpper, M. Okuma, and J. Krüger, "A new process for measuring complete inertia properties," MTZ Worldwide, vol. 74, no. 3, pp. 40-44, 2013.

[16] L.-J. Dong, X.-B. Li, Z.-L. Zhou, G.-H. Chen, and J. Ma, “Threedimensional analytical solution of acoustic emission source location for cuboid monitoring network without pre-measured wave velocity," Transactions of Nonferrous Metals Society of China, vol. 25, no. 1, pp. 293-302, 2015.

[17] L. Dong, X. Li, and G. Xie, "An analytical solution for acoustic emission source location for known P wave velocity system," Mathematical Problems in Engineering, vol. 2014, Article ID 290686, 6 pages, 2014.

[18] Q.-Y. Li, L.-J. Dong, X.-B. Li, Z.-Q. Yin, and X.-L. Liu, "Effects of sonic speed on location accuracy of acoustic emission source in rocks," Transactions of Nonferrous Metals Society of China, vol. 21, no. 12, pp. 2719-2726, 2011.

[19] L.-J. Dong and X.-B. Li, "An efficient closed-form solution for acoustic emission source location in threedimensional structures," AIP Advances, vol. 4, no. 2, Article ID 027110, 2014.
[20] J. A. Somolinos, R. Morales, A. García, and C. Morón, "Piezoelectric sensors system for impact detecting," Sensor Letters, vol. 11, no. 1, pp. 128-130, 2013.

[21] J. A. Somolinos, R. Morales, A. López, and C. Morón, “A new self-calibrated procedure for impact detection and location on flat surfaces," Sensors, vol. 13, no. 6, pp. 7104-7120, 2013. 

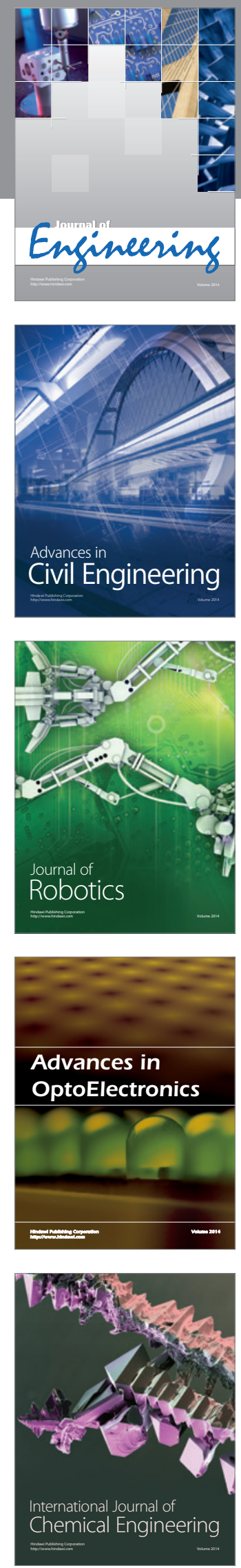

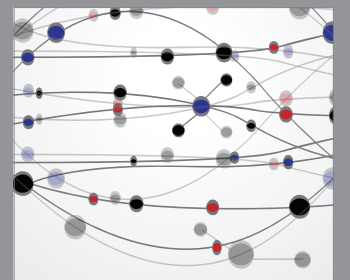

The Scientific World Journal
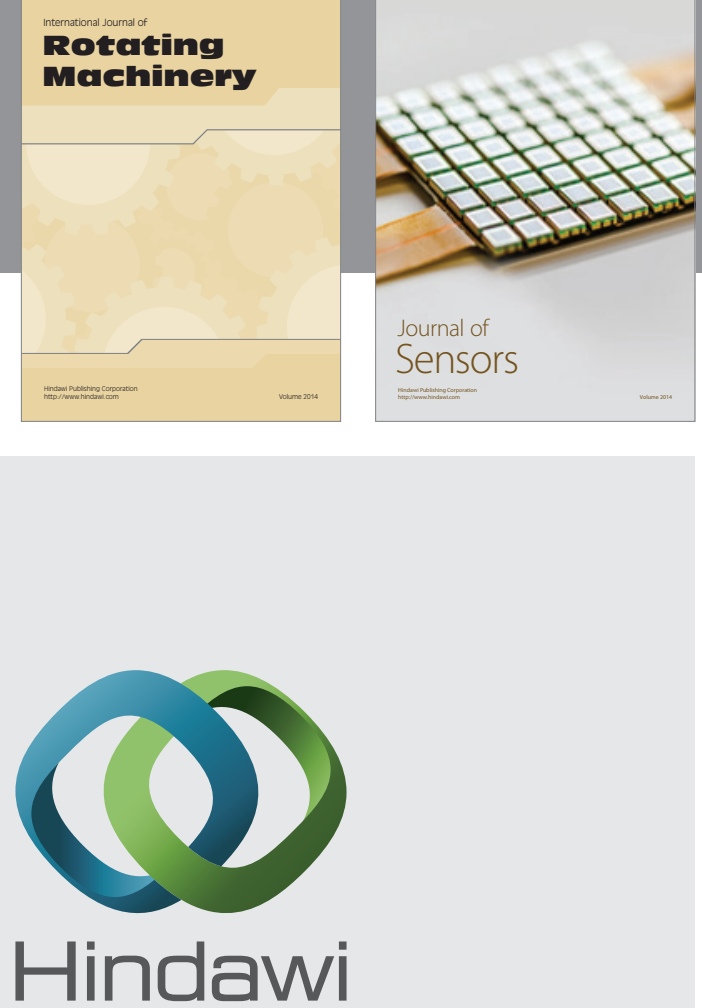

Submit your manuscripts at http://www.hindawi.com
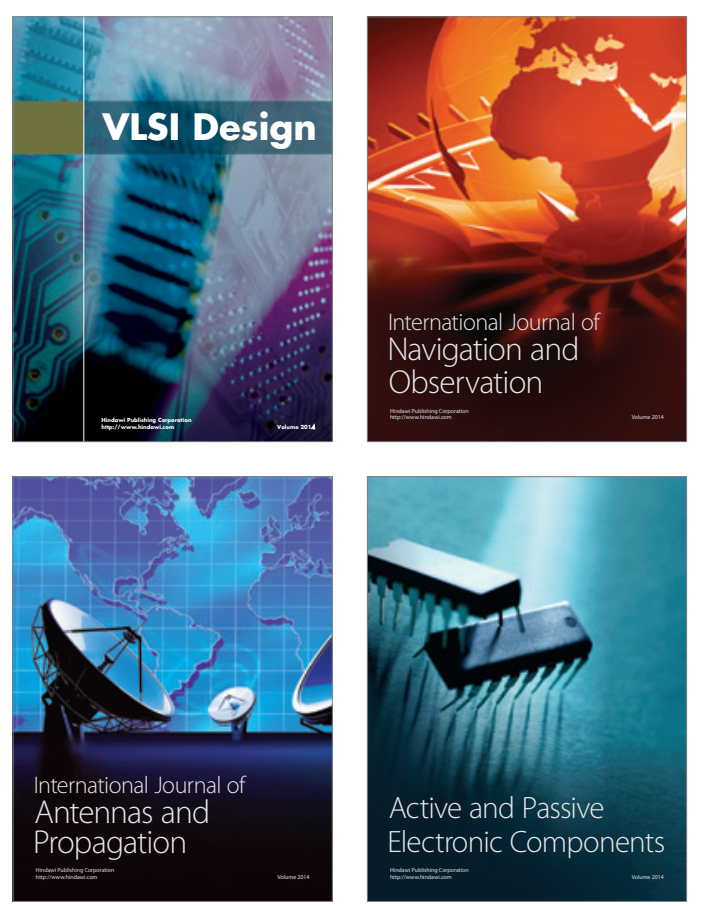
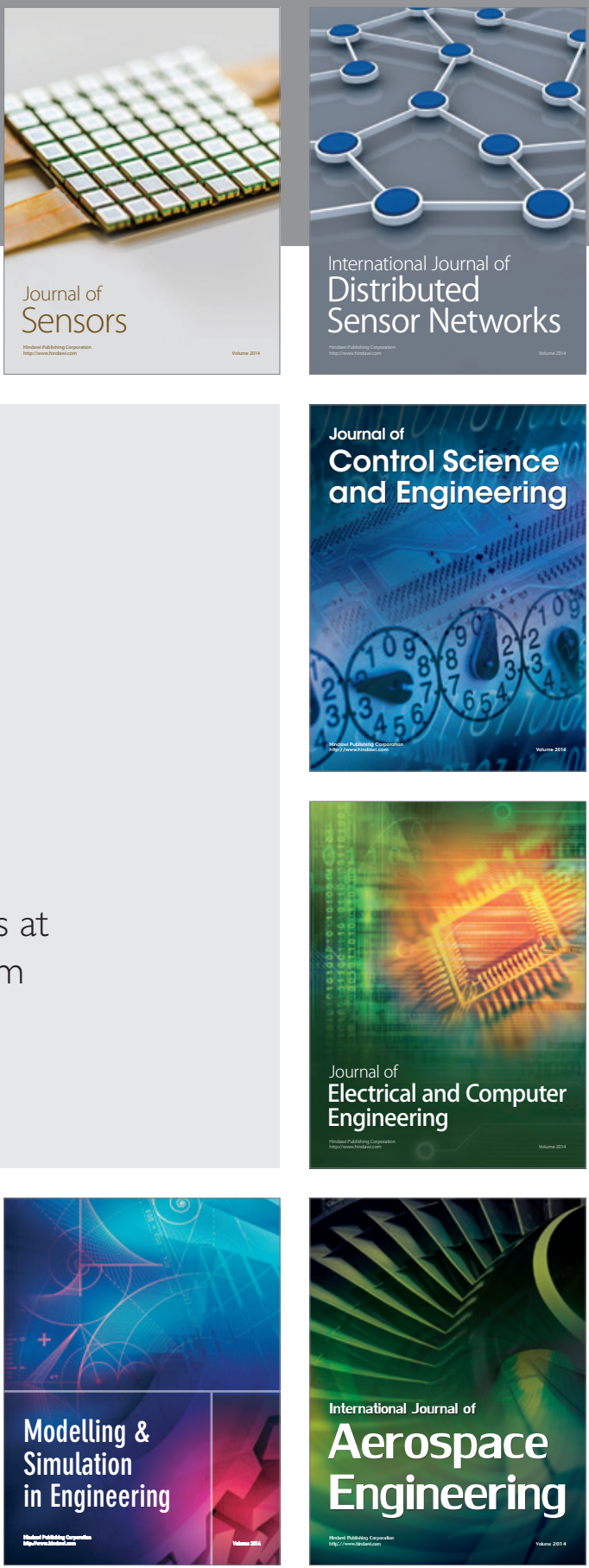

Journal of

Control Science

and Engineering
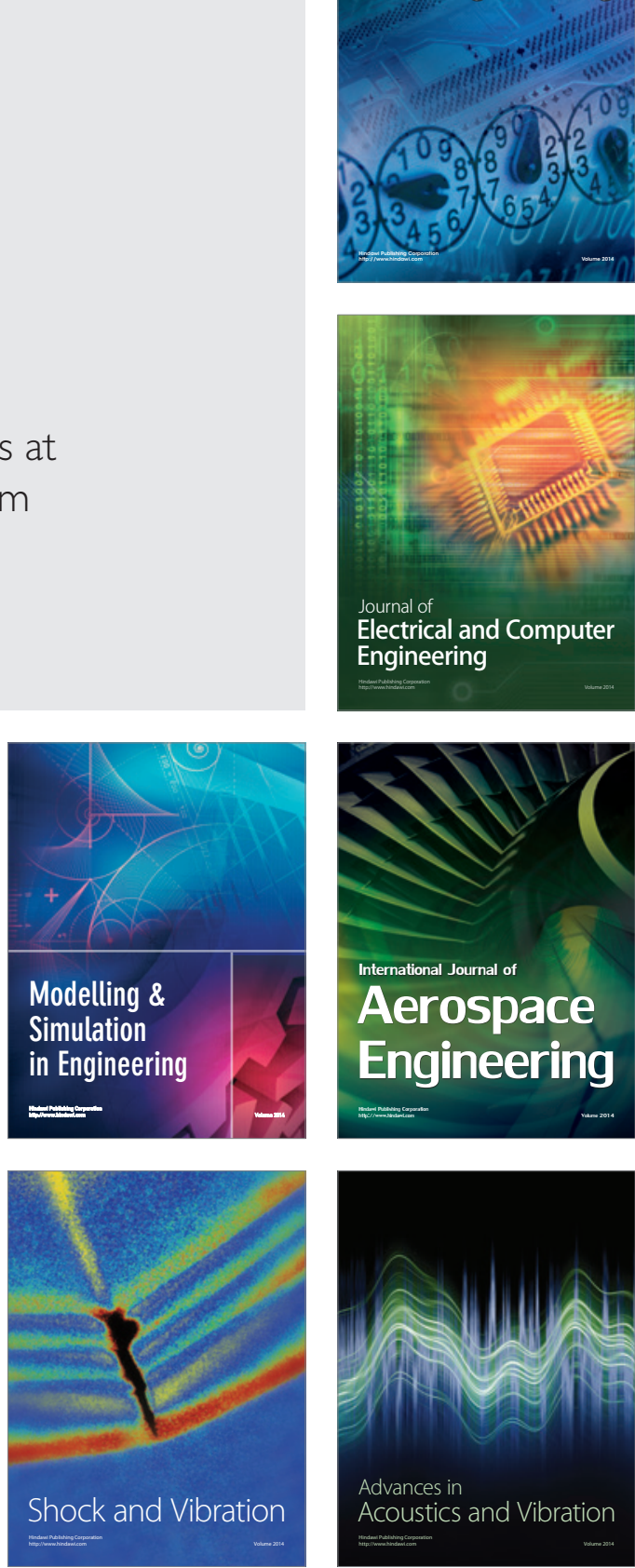